\title{
Step Motor Mode for Automobile Idle Adjuster
}

\author{
Gaoming Ding
}

Jiandong College, CZJDU, Changzhou, China

\begin{abstract}
Automobile idle adjuster is mainly used to make the idle speed of engine be constant and reduce oil cost when automobile is in idle moving, which can increase idle speed and prevent engine from stopping. Automobile idle adjuster controls idle speed by controlling the mode of throttle valve channel. It also can increase idle speed automatically when the engine load is bigger. This can be happen when the air-conditioning unit, power steering or torque converter is introduced. In this paper, we mainly studied the effect, structure, working principle about step motor mode fro automobile idle adjuster. We also introduced the improvement about traditional automobile idle adjuster.
\end{abstract}

Index Terms: Step motor; Idle adjuster; Working principle; Checking methods; Study of improvement

(C) 2011 Published by MECS Publisher. Selection and/or peer review under responsibility of the Research Association of Modern Education and Computer Science.

\section{Introduction}

Automobile idle adjuster is mainly used to make the idle speed of engine be constant and reduce oil cost when automobile is in idle moving, which can increase idle speed and prevent engine from stopping. Automobile idle adjuster controls idle speed by controlling the mode of throttle valve channel. According to the structure characteristics, idle adjuster can be classified five types: bimetal elements, paraffin wax, electromagnetic type, rotary slide valve type and step motor type.

* Corresponding author.

E-mail address: hbxfqxyqxy_123@163.com 


\section{Structure of idle adjuster}

\section{A. Bimetal elements idle adjuster}

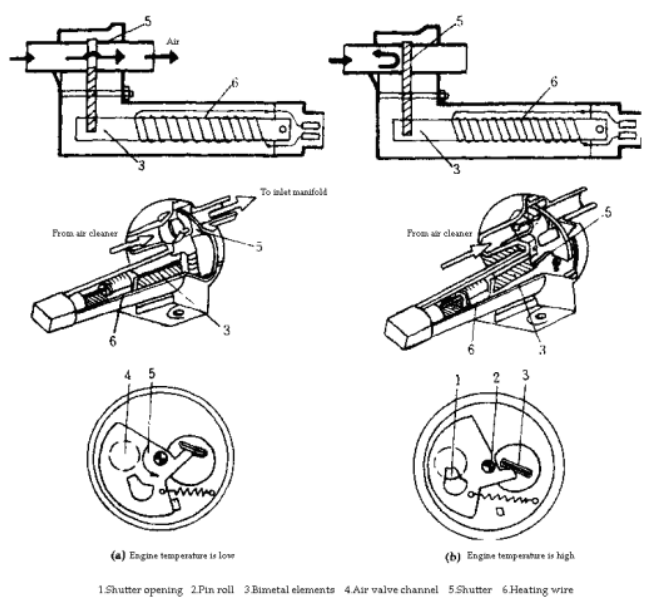

Fig 1. Bimetal elements idle adjuster's structure

Bimetal elements idle adjuster is a kind of rapid idle structure which used to increase air amount by opening air valve when the engine starts to heat. It consists of bimetal elements with heat coil and air valve channel. Fig. 1 shows its structure. The degree of auxiliary air valve's opening is controlled by shutter, and the shutter is controlled by bimetal elements, and the bimetal elements' restoration varies with temperature.

When the engine temperature falls, the shutter will be open and the air amount will be increased because of throttle valve's closing. So the idle speed will be in rapid idle speed state.

When the engine operates, the current flows into idle adjuster's heating wire by means of ignition switch. This will close shutter slowly because of bimetal elements' heating. So the air amount will be fallen, and the engine speed will be fallen, too. After being heated for a while, the shutter will close air valve channel fully, and the engine will get normal idle speed.[1]

\section{B. Paraffin wax idle air adjuster}

Paraffin wax idle air adjuster controls air valve channel sectional area in accordance with engine's cooling liquid temperature. Paraffin wax is solid when its temperature is low, and it will be liquid when the temperature is high. Usually, the volume will be increased when the solid has been changed into liquid. Depending on the characteristic, paraffin wax idle air adjuster can be gotten.
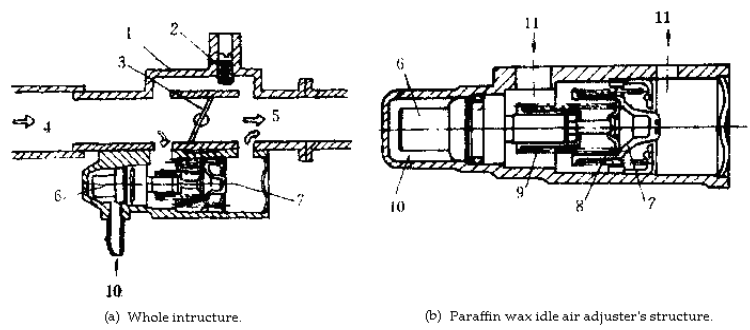

1.Throttle body 2.Idle adjusting bolt 3.Throttle valve 4.From air cleaner 5.To inlet manifold

6 Paraffin wax 7 Cone valve 8 Outer spring 9 Inner spring 10Cooling liquid 11.Air

Fig 2.Paraffin wax idle air adjuster's structure 
Engine cooling liquid is the necessary condition if we accept this kind of air adjuster. In order to simplify its structure, we usually use throttle valve heat the common cooling liquid structure. Fig.2 shows the kind of adjuster's whole structure.

\section{Electromagnetic type air adjuster}

Fig. 3 shows the electromagnetic type air adjuster's structure. It is a kind of proportional electromagnetic valve structure, and it consists of electromagnetic coil and valve axis. It controls the valve's opening and closing by means of electromagnetic attractive force which caused by electromagnetic coil. When the spring force is equal to the electromagnetic attractive force, the degree of valve's opening and closing is stable. Electromagnetic attractive force is dependant on the driving current which from microprocessor control equipment to electromagnetic idle air adjuster's electromagnetic coil. When the current is bigger, the electromagnetic attractive force is bigger, and the valve opens more. On the contrary, the valve opens little. Corrugated pipe is mainly used to eliminate the side effect of valve opening position which caused by valve pressure difference. This kind of idle air adjuster's advantage is that its response speed is very high.[2]

\section{Rotary slide valve type idle adjuster}

Fig.4 shows the structure of rotary slide valve type idle adjuster. It consists of permanent magnet, armature, rotary slide valve, helical pull-off spring, dynamo brush and lead wire. Rotary slide valve is fixed on armature axis, which used to control the air amount flows into slide channel. Permanent magnet is fixed on the shell, which forms magnetic field Armature is located in the magnetic field. It has two groups of electromagnetic coils L1 and L2, whose direction is contrary. When current passes the coil L1, armature rotates with rotary slide valve, so the air side channel sectional area is smaller. On the contrary, while the current passes the coil L2, the air side channel sectional area is bigger.

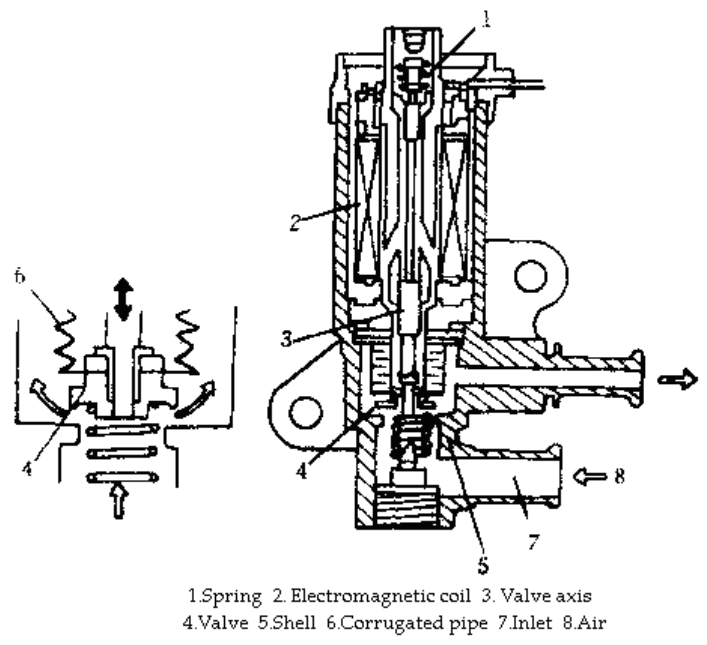

Fig 3.Electromagnetic type air adjuster 


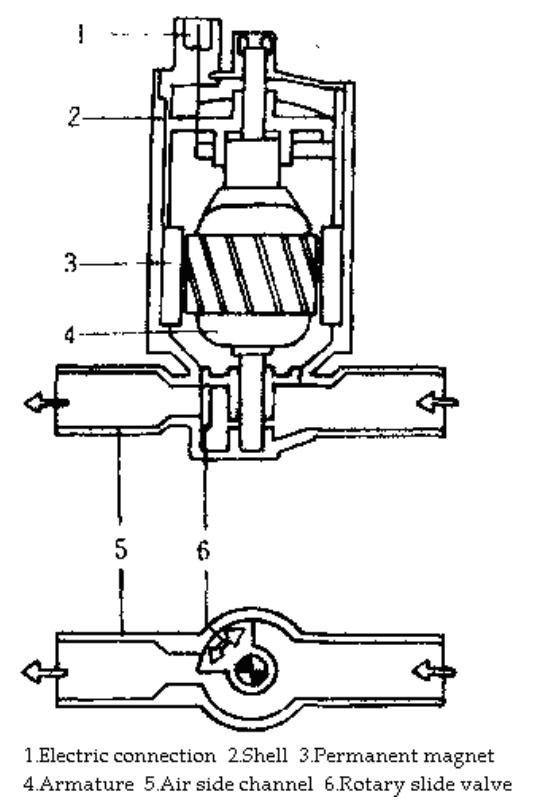

Fig 4.Rotary slide valve type idle adjuster

The two terminals of L1 and L2 are connected with dynamo brush, and they are also connected with ECU by means of dynamo brush. Fig.5 shows the structure. The dynamo brush slip ring is similar to motor commutator's structure. It consists of three parts of slip sheets, and every slip sheet touches dynamo brush. The two terminals of armature coils L1 and L2 are weld the corresponding slip sheet respectively. When the ignition switch is turned on, the idle adjuster is powered by storage battery. The power-up state of armature coils depends on the triodes of VT1 and VT2 which are all controlled by ECU.

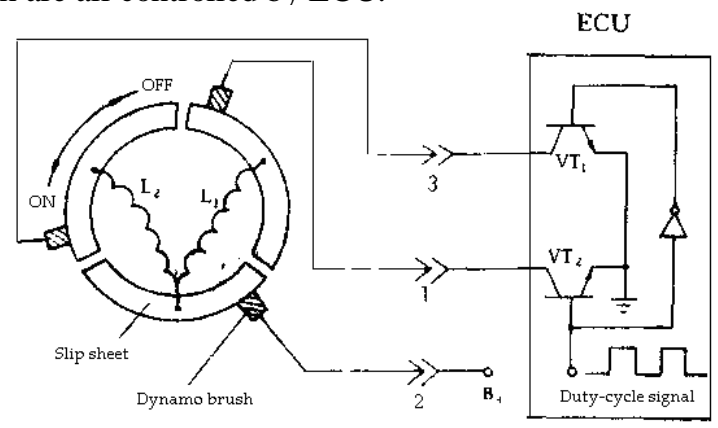

Fig 5.Rotary slide valve type idle adjuster

Because there is a redirector between rotary slide valve and the base of triode VT1, so the output phases of triode VT1 and VT2 are contrary. So the currents in the rotary slide valve idle adjuster's two armature coils are alternative. And the electromagnetic torques which produced on armature is contrary. Because electromagnetic torques' alternative frequency is high, and the rotation of armature has certain inertia, so the rotary slide valve will stabilize the duty cycle which used to control signal. 


\section{Step motor type idle adjuster}

Step motor is a kind of open-loop control component which converts electrical pulse signal into angle displacement or line displacement. When the system is not overload, the motor's speed and the position of stop is only dependant on the pulse signal's frequency and pulse number. This means that a pulse signal introduced in motor, the motor will rotate with a step angle. Because of the linear relationship and the step motor's periodic error, it is easy to control step motor in the domain of speed and position.

Different automobile corporations always use different step motor type idle adjuster. Although their basic principles are same, there are some differences between them. We have taken the products which produced by Nissan and Mitsubishi respectively for example in this paper, and introduced their structure and principle.[3]

Fig.6 shows the step motor idle adjuster's structure. Its rotor is constructed by permanent magnet, and its $\mathrm{N}$ pole and $\mathrm{S}$ pole are arrayed alternatively on cycle surface. And there are eight pairs of magnetic poles. Its stators are constructed by A stator and B stator which are all with coil respectively. The coil is surrounded by claw pole which make by permeability magnetic material. There is a clop phase difference between A pole and B pole. Fig.7 shows the structure.

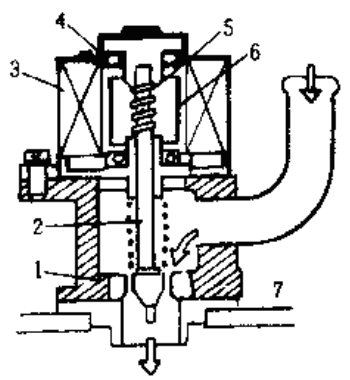

1.Valve base 2.Valve axis 3.Stator 4.Axletree 5.Screw 6.Rotor 7.Valve core

Fig 6.Step motor type idle adjuster

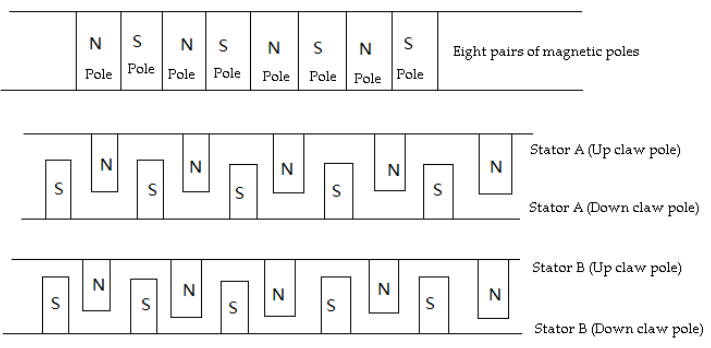

Fig 8.Distribution of stator claw poles
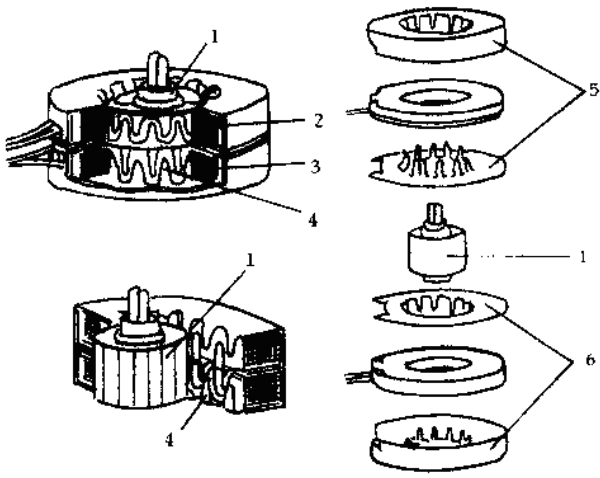

1.Rotor 2.Coil A 3.Coil B 4.Claw pole 5.Stator A 6.Stator B

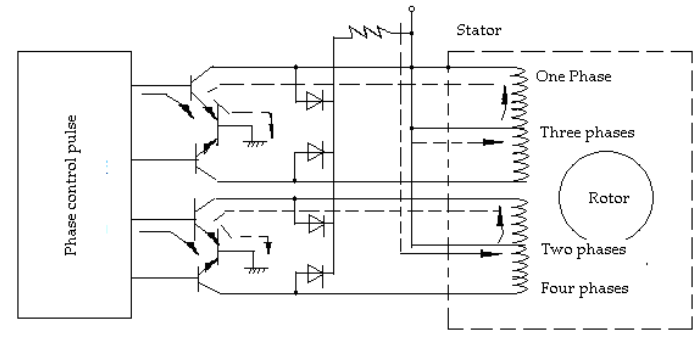

Fig 9.Phase control circuit 


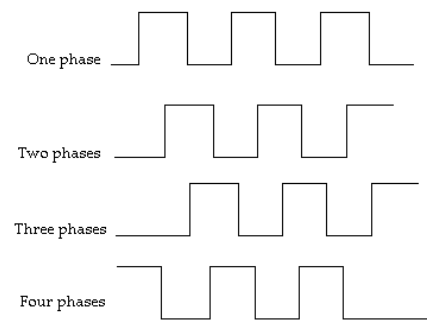

Fig 10.Phase control pulses

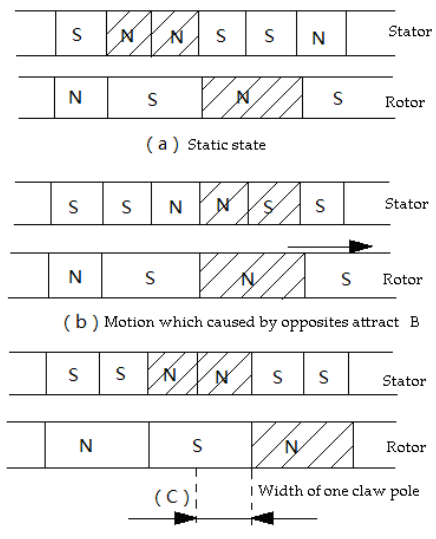

Fig 11.Step principle

The polarity of claw pole is alternative, which is controlled by ECU controlling rotor's pulse. A rotor and B rotor are constructed by coiling one-phase and three-phase and two-phase and four-phase respectively. Fig.9 shows its structure. And Fig.10 shows the phase control pulses. In order to rotate step motor, phase control pulse should be lagged 90 degree phase angle in accordance with one-two-three-four phase sequence. Fig. 11 shows the rotor's motion at the direction of $\mathrm{N}$. On the contrary, if we want to make step motor rotate contrarily, the phase control pulse should exceed 90 degree in accordance with one-two-three-four phase sequence. So the stator $\mathrm{N}$ pole moves to left direction, and the rotor will rotate contrarily.

\section{Improvement of step motor idle adjuster}

The traditional gas engine's idle speed is set before actual using. So, we can't adjust the air cylinder mixture gas and engine speed automatically during the process of using. This makes that idle speed will deviate the original value greatly with the variation of conditions. The engine's controller which equipped electrical-control fuel ejection system can adjust air cylinder mixture gas and engine speed by means of executer in accordance with engine's different conditions. So we can realize a good idle speed object. We have designed a gas engine idle close-loop control system on the basis of the foreign experience.[4]

\section{E. Improved hardware of idle adjuster}

Construction of hardware: The control system hardware mainly consists of sensors, signal processing circuits, $8098 \mathrm{MCU}$ and execution driving circuits. 8098 Microprocessor has been used in this system, its anti-jamming ability is very strong, and it has such advantages as low cost, cheap, high programming efficiency and rapid processing speed. The controllers mainly gather analogue signals, such as rotation speed, starting, idle speed, air flow amount and cooling liquid temperature. The system outputs ejection signal and step motor driving signal. Fig.12 shows the control system's structure.

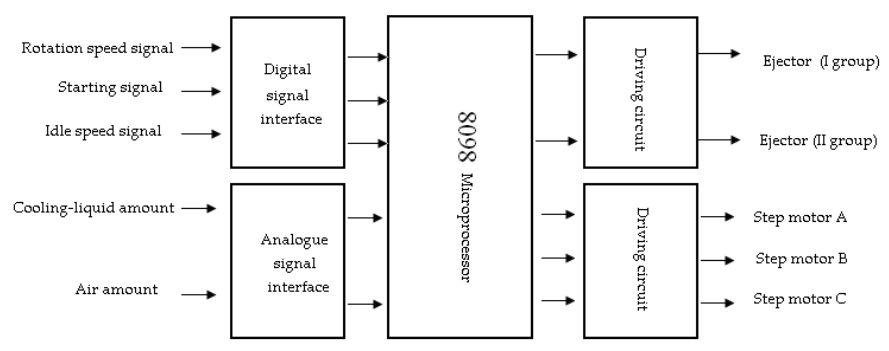

Fig 12.Structure of idle control system 
Principle: Different engine temperature has different idle object speed. The relationship between idle object speed and water temperature comes form engine test, and be stored in Microprocessor's ROM. When the engine operates, the controller detects the object rotation speed which is corresponding to the water temperature and compares with engine's actual speed, and then determines the motor's rotation direction in accordance with rotation speed error and gives the rotation step number in accordance with the error. Because the air adjusting valve rotates with step motor, so the flow area of adjusting valve can be adjusted in real time, which makes air cylinder mixture gas change. Adding mixture gas amount, rotation speed can be increased; reducing the mixture gas amount, the rotation speed can be dropped. And the engine speed will be equal to the object rotation speed eventually.

\section{F. Adjusting equipment of idle speed air flow amount}

Execution structure: The real-time adjusting of mixture gas amount in air cylinder is the key which realizes gas engine idle speed controlling. The executer which used to control idle mixture gas amount can be divided into by-pass air adjusting type and throttle valve control type. These two types can all control air flow amount by adjusting air flow area. The executer of throttle valve control type is very large, which fits for single-point gas ejection system. And the executer of by-pass air adjuster type is small, so it is easy to equip and control. It is fit for multi-point electrical ejection system. In this kind of mode, the executer includes step motor and rotary electromagnetic valve. Here we have used step motor, which can get large air flow amount. On the other hand, idle rotation speed control can be used when the engine is operated on the state of heating. Fig. 13 shows the structure of idle air adjusting equipment.

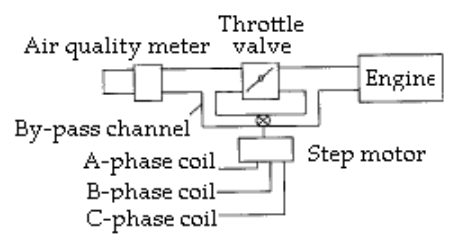

Fig 13.Structure of idle speed air flow amount adjusting equipment

Control of step motor: Step motor is a kind of executing component which converts electrical pulse signal into mechanical movement. Its input pulse number not only is corresponding to the output angle displacement, but also is step with time. The given pulse number can realize the control of load and the speed control by changing input pulse frequency. Step motor has such advantages as high location precision and low error. 


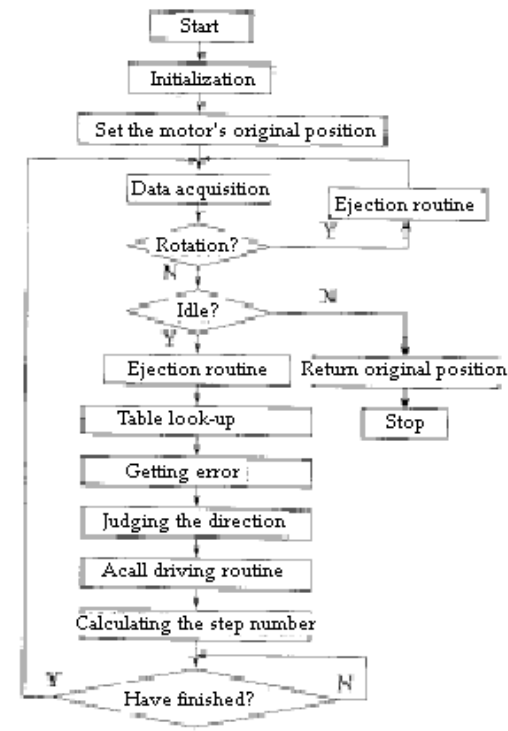

Fig 14.Idle speed control system software

Three-phase step motor and three-phase \& six-beat control mode have been used this system. The motor's step distance angle is 1.5 degree. The designed step motor driving program can realize such functions as motor's rotation, auto-lock, auto-tracking and writing starting position and recoding the number of rotation.

\section{G. Idle speed control system software}

Fig.14 shows the system control software's flow chart. During the process of designing software, we have used software digital filtering, which can increase the ability of anti-jamming. On the other hand, we have used module subroutines, which facilitate the whole design.

\section{Comparison test}

In order to verify the validity of idle speed control system, we have tested on the basis of CA488Q gas engine. We have compared idle speed close-loop control electrical ejection system with carburetor type engine. We using dynamometer to simulate the affection of engine idle speed load. The idle speed object speed has been set $800 \mathrm{r} / \mathrm{min}$ and $900 \mathrm{r} / \mathrm{min}$ respectively. Fig. 15 shows the test result.

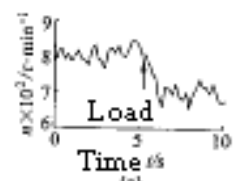

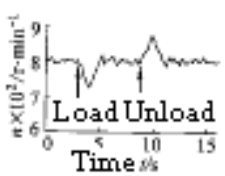

(b)

(a) Original engine (b) Idle speed close-loop

Fig 15.Comparison of idle speed stability (Object idle speed is $800 \mathrm{r} / \mathrm{min}$ ) 


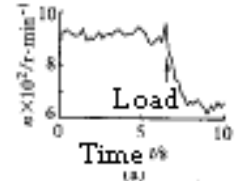

(a) Original engine

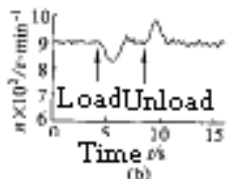

(b)Idle speed close-loop control engine

Fig 16.Comparison of idle speed stability (Object idle speed is $900 \mathrm{r} / \mathrm{min}$ )

From the conclusions, we can conclude that engine idle speed motion can be reduced greatly after being used close-loop control. Close-loop control idle speed can reach the object speed rapidly. Comparing with the original engine's idle speed curve, electrical control system has apparent advantages.

\section{Conclusions}

Increasing idle speed stability is the key which increasing idle operating quality. On the basis of having analyzed idle speed stability, we have designed gas engine idle speed close-loop control system. And this can increase idle speed operating quality greatly.

\section{References}

[1] Lars Kjergaard, Steffen Nielsen, Thomas Vesterholm et al. Advanced nonlinear engine idle speed control system. SAE paper 940974, 1994.

[2] Yi Feng, The latest exhaust gas turbo-mechanical compound supercharging Stratified charge and direct injection gasoline engine(3)[J], AUTOMOBILE \& PARTS, 2007(47)

[3] HAO Xiao-hong, JIN Fang-yi, An AC servosystem with 8098 monolithic computer intelligent control for BDCM[J], JOURNAL OF GANSU UNIVERSITY OF TECHNOLOGY, 2000 26(2)

[4] LI Xiao-hong ZHANG Da-fang, An Energy Efficient Topology Control for Ad Hoc Networks with Steered Beam Antennas[J], ACTA ELECTRONICA SINICA, 2010 38(6) 